\title{
Clinical and therapeutic features and prognostic factors of metastatic colorectal cancer over age 80: a retrospective study
}

Hiroyuki Hisada ${ }^{1} 2^{*}$, Yu Takahashi ${ }^{1}$, Manabu Kubota ${ }^{2}$, Haruhisa Shimura $^{2}$, Ei Itobayashi ${ }^{2}$, Kenji Shimura ${ }^{2}$ and Akira Nakamura ${ }^{2}$

\begin{abstract}
Background: Colorectal cancer (CRC) is one of the most common cancers in the world. The number of elderly patients with CRC increases due to aging of the population. There are few studies that examined chemotherapy and prognostic factors in metastatic colorectal cancer (mCRC) patients aged $\geq 80$ years. We assessed the efficacy of chemotherapy and prognostic factors among patients with $\mathrm{mCRC}$ aged $\geq 80$ years.

Methods: We retrospectively analyzed clinical and laboratory findings of 987 patients newly diagnosed with CRC at Asahi General Hospital (Chiba, Japan) between January 2012 and December 2016. The Kaplan-Meier method was used for the overall survival (OS) and the log-rank test was used to identify difference between patients. A multivariate Cox proportional hazard regression analysis was performed to determine the hazard ratios and 95\% confidence intervals (Cls) of prognostic factors among super-elderly patients.

Results: In total, 260 patients were diagnosed with mCRC (super-elderly group: $n=43$, aged $\geq 80$ years and younger group, $n=217$, aged $<80$ years). The performance status and nutritional status were worse in the super-elderly group than in the younger group. The OS of super-elderly patients who received chemotherapy was worse than that of younger patients (18.5 vs. 28.8 months; $P=0.052)$, although the difference was not significant. The OS of patients who received chemotherapy tended to be longer than that of those who did not; however, there were no significant differences in OS in the super-elderly group (18.5 vs. 8.4 months $P=0.33$ ). Multivariate analysis revealed that carcinoembryonic antigen levels $\geq 5 \mathrm{ng} / \mathrm{mL}$ (hazard ratio: $2.27 ; 95 \% \mathrm{Cl} 1.09-4.74 ; \mathrm{P}=0.03$ ) and prognostic nutritional index $\leq 35$ (hazard ratio: $8.57 ; 95 \% \mathrm{Cl} 2.63-27.9 ; \mathrm{P}=0.0003$ ) were independently associated with poor OS in the super-elderly group.
\end{abstract}

Conclusions: Patients with $\mathrm{mCRC}$ aged $\geq 80$ years had lower OS than younger patients even though they received chemotherapy. Carcinoembryonic antigen and prognostic nutritional index were independent prognostic factors in super-elderly patients with $\mathrm{mCRC}$, but chemotherapy was not.

Trial registration: retrospectively registered.

Keywords: Colorectal cancer, Elderly, Prognostic factor, Nutritional status, Chemotherapy

*Correspondence: hisada-hiroyuki326@g.ecc.u-tokyo.ac.jp

1 Department of Gastroenterology, Graduate School of Medicine, the University of Tokyo, 7-3-1 Hongo, Bunkyo-ku, Tokyo 113-8655, Japan Full list of author information is available at the end of the article

\section{Background}

Colorectal cancer (CRC) is the third most common cancer worldwide, and about $82 \%$ of patients diagnosed with sporadic colon cancer are aged $\geq 60$ years [1]. The median age of patients diagnosed with CRC in developed 
countries is 70 years. Among patients aged $\geq 80$ years in the United States, approximately $19 \%$ are men and $29 \%$ women [2]. The life expectancy of a Japanese 80-year-old was 88.9 years in men and 91.8 years in women in 2017 [3]. The proportion of elderly patients who undergo surgery, receive chemotherapy, or both increases in clinical practice [4]. However, old age is considered a risk factor for complications because elderly patients usually have comorbidities and are frail [5]. Due to advancements in chemotherapy, the prognosis of young patients with unresectable metastatic CRC (mCRC) has improved, but that of elderly patients with mCRC has not improved [6]. Standard chemotherapy regiments for mCRC are based on doublet chemotherapy agents, such as fluoropyrimidine plus oxaliplatin or irinotecan combined with a molecular-targeted agent (bevacizumab, cetuximab, or panitumumab) for healthy patients. Meanwhile, the efficacy of combination chemotherapy based on oxaliplatin or irinotecan in super-elderly patients remains unelucidated. Therefore, chemotherapy is often administered to remove oxaliplatin or irinotecan from standard treatment in elderly patients according to a randomized phase 3 trial [7].

Several studies have attempted to evaluate chemotherapy in elderly patients. However, most of them have included elderly patients aged $\geq 65$ years with $\mathrm{mCRC}$, and others have included patients aged $\geq 70$ years or patients of different ages [7-9]. Moreover, super-elderly patients (aged $\geq 80$ years) have worse performance status (PS) and more comorbidities than younger patients. Clinical trials cautiously select participants (with the application of age restriction during study enrolment and with consideration of patients with good PS and comorbidities); therefore, elderly patients are significantly under-represented [10-12]. Only few studies showed the clinical characteristics of patients with $\mathrm{mCRC}$ aged $\geq 80$ years and the survival benefits of surgical resection and chemotherapy in these patients [13-15].

Primary tumor resection, carcinoembryonic antigen (CEA), chemotherapy, microsatellite instability, RAS$B R A F$ mutation, and prognostic nutritional index (PNI) have been identified as the prognostic factors of mCRC [16-18]. However, few studies have analyzed prognostic factors specifically for the super-elderly patients.

Hence, the current study aimed to investigate the efficacy of chemotherapy and whether the prognostic factors described in previous reports apply to super-elderly patients with mCRC.

\section{Methods}

This study was approved by the institutional review board of Asahi General Hospital (approval no. 2019031914). Due to the use of anonymous data, instead of obtaining informed consent, information about the study, and the option to drop out was provided to the participants. This study was performed in accordance with the standards of the Declaration of Helsinki and the current ethical guidelines. This was a cross-sectional retrospective study, and all medical records were retrospectively reviewed.

Patients whose CRC diagnosis was confirmed between January 2012 and December 2016 based on histological examination or colonoscopy and radiologic images, such as computed tomography (CT) and magnetic resonance imaging (MRI), were included. Patients with localized colorectal cancer and radical R0 resections were excluded. Staging was performed using the International Union for Cancer Control TNM classification 7th ed.

The diagnosis of CRC was confirmed on colonoscopy and pathological examinations and on imaging studies, such as CT and MRI. We analyzed the medical records until December 2019.

\section{Data collection}

Data on the characteristics of the patients, including age, sex, tumor location, metastatic site, Eastern Cooperative Oncology Group PS score, histopathology reports, serum CEA level, body mass index (BMI), creatinine and albumin levels, PNI, chemotherapy, and OS, were extracted. Serum samples were collected and tested when the patients were diagnosed with mCRC. OS was defined as the period from the diagnosis of mCRC to the date of death or last follow-up. Adverse events were defined according to the National Cancer InstituteCommon Toxicity Criteria version 4.0. Eastern Cooperative Oncology Group PS score was defined based on a previous study [19]. Poorly differentiated cancer was defined as tumor with $5 \%-50 \%$ glandular structure, and signet-ring cell carcinoma was defined as the presence of $>50 \%$ of tumor cells with prominent intracytoplasmic mucin [20]. The PNI was calculated as follows: $10 \times$ albumin value $(\mathrm{g} / \mathrm{dL})+0.005 \times \mathrm{TLC}$ of the peripheral blood, where TLC is the total lymphocyte count $/ \mathrm{mm}^{3}$. BMI was classified as either $<18.5$ or $\geq 18.5 \mathrm{~kg} / \mathrm{m}^{2}$ and PNI as either as either $<35$ and $\geq 35$, based on previous reports $[21,22]$. Patients with cecum, ascending colon, and transverse colon cancer were categorized under the right-side group, and those with descending, sigmoid colon, and rectal cancer were categorized under the left-side group [23].

\section{Statistical analysis}

All statistical analyses were performed with EZR (Saitama Medical Center, Jichi Medical University, Saitama, Japan), which is a graphical user interface for R (The R Foundation for Statistical Computing, Vienna, Austria). Comparisons between groups were made 
using the Mann-Whitney $U$ test for continuous and ordinal variables and the chi-square test for categorical variables. The Kaplan-Meier method was utilized to analyze the OS, and the log-rank test was used to identify differences between the patients. To assess the impact of some factors on the OS, univariate, and multivariate analyses of OS were performed using the Cox proportional hazard model. Data were summarized with hazard ratio along with $95 \%$ confidence interval (CI). The variables with $\mathrm{P}$ values $<0.10$ in the univariate model were included in the multivariate model. Missing data were excluded from the analysis. All reported $P$ values were two-tailed, and $P$ values $<0.05$ were considered statistically significant.

\section{Results}

Between January 2012 and December 2016, 987 patients were newly diagnosed with CRC. Of them, 702 patients with localized colorectal cancer and 25 patients who received radical R0 surgery were excluded. Finally, 260 patients with $\mathrm{mCRC}$ were evaluated. We stratified the patients into two groups according to age at the time of diagnosis: the super-elderly group $(n=43, \geq 80$ years) and the younger group ( $n=217,<80$ years).

A detailed flowchart of the inclusion and exclusion criteria is presented in Fig. S1 (in the Additional file 1).

\section{Characteristics of the participants}

The clinical and pathological characteristics of the patients $(n=260)$ are presented in Table 1.

The proportion of patients with good PS was lower in the super-elderly group than in the younger group (65\% vs. $91 \% ; \mathrm{P}<0.0001)$. The $\mathrm{BMI}(21.4$ vs. $22.9 ; \mathrm{P}=0.03)$ and PNI (42.6 vs. $46.2 ; \mathrm{P}=0.04$ ) of the super-elderly group were lower than those of the younger group. The creatinine and albumin levels were not significantly different between the two groups. The proportion of patients with poorly differentiated cancer or signet-ring cell carcinoma was higher in the super-elderly group than in the younger group $(21 \%$ vs. $6 \%$; $<0.0001)$.

\section{Treatment}

No significant differences were found between the two groups in terms of the resection rate of primary and metastatic tumors. The number of patients who received chemotherapy in the super-elderly group was significantly lower than that in the younger group ( $28 \%$ vs. $84 \%$; $\mathrm{P}<0.0001$ ).

These data are summarized in Table 2.

\section{Chemotherapy}

Only $12 / 43$ patients (28\%) in the super-elderly group received chemotherapy, and the prescribed chemotherapeutic agents were capecitabine, 5-FU/LV, oxaliplatin,

Table 1 Baseline Characteristics of patients diagnosed with $\mathrm{mCRC}$, separated according to those aged $<80$ and $\geq 80$ years old

\begin{tabular}{|c|c|c|c|}
\hline \multirow[t]{2}{*}{ Variable } & \multirow{2}{*}{$\begin{array}{l}\text { Younger group }(n=217) \\
n \text { or median (range) }\end{array}$} & \multicolumn{2}{|c|}{ Super elderly group $(n=43)$} \\
\hline & & $\mathrm{n}$ or median (range) & $P$ \\
\hline Age(years) & $68(27-79)$ & $83(80-93)$ & $<0.0001$ \\
\hline Male sex (\%) & $135(62 \%)$ & $21(49 \%)$ & 0.11 \\
\hline PS score of $0-1$ & 197 (91\%) & $28(65 \%)$ & $<0.0001$ \\
\hline Primary site & & & 0.32 \\
\hline Colon & $187(86 \%)$ & $40(93 \%)$ & \\
\hline Rectum & $30(14 \%)$ & $3(7 \%)$ & \\
\hline Tumor located in the right-side & $83(38 \%)$ & $11(26 \%)$ & 0.12 \\
\hline \multicolumn{4}{|l|}{ Site of metastases } \\
\hline Liver only & $80(37 \%)$ & $15(35 \%)$ & 0.86 \\
\hline Lung only & $19(9 \%)$ & $7(16 \%)$ & 0.16 \\
\hline Liver and lung & $35(16 \%)$ & $7(16 \%)$ & 1 \\
\hline Other & $88(41 \%)$ & $14(33 \%)$ & 0.39 \\
\hline Albumin level (g/dL) & 3.8 & 3.7 & 0.21 \\
\hline $\mathrm{BMI}$ & 22.9 & 21.4 & 0.03 \\
\hline PNI & 46.2 & 42.6 & 0.04 \\
\hline Creatinine level (mg/dL) & 0.77 & 0.84 & 0.1 \\
\hline CEA level (ng/mL) & 20.1 & 11.4 & 0.04 \\
\hline RAS mutation type & $78(46 \%)$ & $7(54 \%)$ & 0.58 \\
\hline $\begin{array}{l}\text { Poorly differentiated cancer or signet-ring cell } \\
\text { carcinoma }\end{array}$ & $14(6 \%)$ & $9(21 \%)$ & $<0.0001$ \\
\hline
\end{tabular}


Table 2 Treatments administered to patients with mCRC, separated according to those $<80$ and $\geq 80$ years old

\begin{tabular}{lccc}
\hline Variable & $\begin{array}{l}\text { Younger } \\
\text { group } \\
(\mathbf{n}=\mathbf{2 1 7}) \\
\mathbf{n} \text { (range) }\end{array}$ & \multicolumn{2}{l}{$\begin{array}{l}\text { Super-elderly group } \\
\mathbf{( n = 4 3 )}\end{array}$} \\
\cline { 4 - 5 } & $\mathbf{n}$ (range) & P value \\
\hline Resection of primary tumor & $152(70 \%)$ & $32(74 \%)$ & 0.7 \\
Chemotherapy & $182(84 \%)$ & $12(28 \%)$ & $<0.0001$ \\
No treatment & $34(16 \%)$ & $31(72 \%)$ & $<0.0001$ \\
\hline
\end{tabular}

bevacizumab, and panitumumab. Of them, 10 (83\%) received combination chemotherapy, and the most common $(n=9,75 \%)$ combination was a fluoropyrimidine plus oxaliplatin, with or without a moleculartargeted agent. Of the 12 patients who had first-line palliative chemotherapy, only $5(42 \%)$ received chemotherapy for $>6$ months, although most patients in the younger group $(\mathrm{n}=152,84 \%)$ received chemotherapy for $>6$ months. In addition, only 5 (42\%) patients and only $1(8 \%)$ patient in the super-elderly group received second-line and third-line chemotherapy, respectively. Meanwhile, most (128) patients in the younger group (70\%) and 78 (43\%) patients received second-line and third-line chemotherapy, respectively. A summary of the chemotherapy regimens is presented in Table S1 (in the Additional files 2).

Patients who received chemotherapy had significantly better PS than those who did not receive it in the superelderly group ( $100 \%$ vs. $34 \%$; $\mathrm{P}=0.006)$. Albumin levels and PNI of patients who received chemotherapy were higher than those who did not receive it in the superelderly group ( 4.1 vs. $3.4 \mathrm{~g} / \mathrm{dl}$; $\mathrm{P}=0.005$ and 48.9 vs. 42.1 ; $\mathrm{P}=0.009)$.

\section{Adverse events}

Grade 3 or 4 adverse events in first-line chemotherapy were reported in $31.9 \%$ and $66.7 \%$ of patients in the younger and super-elderly groups, respectively $(P=0.02)$. The most frequent adverse events $\geq$ grade 3 in the younger group were neutropenia, with grade 3 or 4 neutropenia reported in $14.3 \%$ of patients; meanwhile, the most frequent adverse events $\geq$ grade 3 in the superelderly group were fatigue, with grade 3 or 4 fatigue reported in $33.3 \%$ of patients. Meanwhile, super-elderly patients receiving mono-chemotherapy $(n=2)$ did not report any grade 3 or 4 adverse events. These data are summarized in Table 3.

\section{Prognostic factors of OS}

The results of the univariate and multivariate analyses of OS in the super-elderly and younger groups are shown in Tables 4 and 5, respectively. The univariate analysis in the
Table 3 Adverse events, separated according to those $<80$ and $\geq 80$ years old

\begin{tabular}{lcll}
\hline Variable & $\begin{array}{l}\text { Younger } \\
\text { group } \\
\text { (n= 182) } \\
\text { n (range) }\end{array}$ & & \multicolumn{2}{l}{$\begin{array}{l}\text { Super-elderly } \\
\text { group }(\mathbf{n}=\mathbf{1 2})\end{array}$} \\
\cline { 3 - 5 } & $\mathbf{n}$ (range) & P value \\
\hline Any toxicity Grade $\geq 3$ & $58(31.9 \%)$ & $8(66.7 \%)$ & 0.02 \\
fatigue Grade $\geq 3$ & $3(1.6 \%)$ & $4(33.3 \%)$ & 0.003 \\
Anorexia Grade $\geq 3$ & $6(3.2 \%)$ & $2(16.7 \%)$ & 0.08 \\
Diarrhoea Grade $\geq 3$ & $1(0.5 \%)$ & $0(0 \%)$ & 1 \\
Neurosensory Grade $\geq 3$ & $17(9.3 \%)$ & $0(0 \%)$ & 0.61 \\
hand-foot syndrome Grade $\geq 3$ & $2(1.1 \%)$ & $0(0 \%)$ & 1 \\
Neutropenia Grade $\geq 3$ & $26(14.3 \%)$ & $1(8.3 \%)$ & 1 \\
\hline
\end{tabular}

super-elderly group (Table 4) revealed that a PS score of $2-4, \mathrm{PNI} \leq 35$, CEA level $\geq 5 \mathrm{ng} / \mathrm{mL}$, and resection of primary tumors were significantly associated with OS. Based on the multivariate analysis, a CEA level $\geq 5 \mathrm{ng} / \mathrm{mL}$ (hazard ratio: $2.27 ; 95 \% \mathrm{CI} 1.09-4.74 ; \mathrm{P}=0.03)$ and $\mathrm{PNI} \leq 35$ (hazard ratio: 8.57 ; 95\% CI 2.63-27.9; $\mathrm{P}=0.0003$ ) were independently associated with poor OS.

In the multivariate analysis, resection of primary tumors (hazard ratio: 0.44; 95\% CI 0.31-0.64; $\mathrm{P}<0.0001$ ) and chemotherapy (hazard ratio: 0.22 ; 95\% CI 0.13-0.37; $\mathrm{P}<0.0001$ ) were identified as significant, independent, and good prognostic factors in the younger group (Table 5). By contrast, OS was significantly reduced when the albumin level was $\leq 3.5 \mathrm{~g} / \mathrm{dL}$ (hazard ratio: $1.61 ; 95 \%$ CI 1.13-2.28; $\mathrm{P}=0.008)$. These data are summarized in Tables 4 and 5 .

\section{Survival}

During the follow-up period, 35 (81\%) patients in the super-elderly group and 140 (65\%) in the younger group died. All 35 patients in the super-elderly group died of primary cancer. On the other hand, in the younger group, 132 patients died of primary cancer, 5 died of pneumonia, 1 died of acute arterial occlusion, 1 died of intestinal perforation, and 1 died of other cancers. There were significant differences in terms of the median OS between the two groups ( 14.0 vs. 25.8 months; $\mathrm{P}<0.0001)$. The $1-$ and 3 -year OS in the younger group were $79 \%$ and $37 \%$, respectively, and those in the super-elderly group were $54 \%$ and $14 \%$, respectively. These data are summarized in Fig. 1.

The median OS of patients in super-elderly patients was significantly different between patients with $\mathrm{PNI} \leq 35$ and PNI $>35$ (3.4 months vs 15.4 months, $\mathrm{P}=0.001)$. These data are summarized in Fig. 2.

The median OS of patients in the super-elderly group who received chemotherapy was 18.5 months, and that 
Table 4 Analysis of prognostic factors in the super-elderly group

\begin{tabular}{|c|c|c|c|c|}
\hline \multirow[t]{2}{*}{ Variables } & \multicolumn{2}{|l|}{ Univariate analysis } & \multicolumn{2}{|l|}{ Multivariate analysis } \\
\hline & Hazard ratio $(95 \% \mathrm{Cl})$ & $P$ value & Hazard ratio $(95 \% \mathrm{Cl})$ & $P$ value \\
\hline Sex (male/female) & $0.85(0.43-1.66)$ & 0.63 & & \\
\hline PS score of 2-4 & $2.07(0.99-4.29)$ & 0.052 & $0.98(0.35-2.75)$ & 0.98 \\
\hline Tumor located on the right side & $1.23(0.59-2.57)$ & 0.58 & & \\
\hline Albumin level $\leq 3.5 \mathrm{~g} / \mathrm{dL}$ & $1.56(0.80-3.07)$ & 0.19 & & \\
\hline $\mathrm{BMI} \leq 18.5$ & $1.74(0.66-4.54)$ & 0.26 & & \\
\hline $\mathrm{PNI} \leq 35$ & $6.15(2.00-18.9)$ & 0.001 & $8.57(2.63-27.9)$ & 0.0003 \\
\hline Creatinine level $\geq 1.5 \mathrm{mg} / \mathrm{dL}$ & $1.78(0.61-5.20)$ & 0.29 & & \\
\hline CEA level $\geq 5 \mathrm{ng} / \mathrm{mL}$ & $1.85(0.91-3.77)$ & 0.089 & $2.27(1.09-4.74)$ & 0.03 \\
\hline RAS mutation type & $1.20(0.36-4.02)$ & 0.76 & & \\
\hline $\begin{array}{l}\text { Poorly differentiated cancer or signet-ring } \\
\text { cell carcinoma }\end{array}$ & $0.64(0.28-1.51)$ & 0.3 & & \\
\hline Resection of primary tumor & $0.41(0.18-0.92)$ & 0.026 & $0.45(0.20-1.04)$ & 0.06 \\
\hline Chemotherapy & $0.68(0.32-1.47)$ & 0.33 & & \\
\hline
\end{tabular}

Table 5 Analysis of prognostic factors in the younger group

\begin{tabular}{|c|c|c|c|c|}
\hline \multirow[t]{2}{*}{ Variables } & \multicolumn{2}{|l|}{ Univariate analysis } & \multicolumn{2}{|l|}{ Multivariate analysis } \\
\hline & Hazard ratio $(95 \% \mathrm{Cl})$ & $P$ value & Hazard ratio $(95 \% \mathrm{Cl})$ & $P$ value \\
\hline Sex (male/female) & $1.09(0.77-1.54)$ & 0.63 & & \\
\hline PS score of $2-4$ & $3.49(1.86-6.54)$ & $<0.0001$ & $1.16(0.57-2.35)$ & 0.68 \\
\hline Tumor located on the right side & $1.02(0.72-1.44)$ & 0.92 & & \\
\hline Albumin level $\leq 3.5 \mathrm{~g} / \mathrm{dL}$ & $1.60(1.13-2.26)$ & 0.008 & $1.61(1.13-2.28)$ & 0.008 \\
\hline $\mathrm{BMI} \leq 18.5$ & $1.08(0.62-1.88)$ & 0.79 & & \\
\hline $\mathrm{PNI} \leq 35$ & $1.38(0.84-2.27)$ & 0.21 & & \\
\hline Creatinine level $\geq 1.5 \mathrm{mg} / \mathrm{dL}$ & $0.62(0.25-1.53)$ & 0.30 & & \\
\hline CEA level $\geq 5 \mathrm{ng} / \mathrm{mL}$ & $1.35(0.89-2.04)$ & 0.16 & & \\
\hline RAS mutation type & $1.06(0.72-1.54)$ & 0.78 & & \\
\hline $\begin{array}{l}\text { Poorly differentiated cancer or signet-ring } \\
\text { cell carcinoma }\end{array}$ & $0.74(0.38-1.46)$ & 0.38 & & \\
\hline Resection of primary tumor & $0.45(0.31-0.64)$ & $<0.0001$ & $0.44(0.31-0.64)$ & $<0.0001$ \\
\hline Chemotherapy & $0.23(0.14-0.38)$ & $<0.0002$ & $0.22(0.13-0.37)$ & $<0.0001$ \\
\hline
\end{tabular}

of patients in the younger group was 28.8 months, and the difference in median OS between the two groups was close to significance $(\mathrm{P}=0.052)$. These data are summarized in Fig. 3.

There were no significant differences in the median OS between those who received chemotherapy and those did not receive it in the super-elderly group. The OS of patients who received chemotherapy was not significantly prolonged (18.5 vs. 8.4 months; $\mathrm{P}=0.33$ ), and a similar trend was observed even in patients with PNI values $>35$ ( 18.5 vs. 12.9 months; $\mathrm{P}=0.64)$. These data are summarized in Fig. 4a, b

\section{Discussion}

The current study showed that low PNI and high CEA levels were poor prognostic factors for $\mathrm{mCRC}$ in the super-elderly group and chemotherapy was not a prognostic factor for $\mathrm{mCRC}$ in the super-elderly group. Only few studies of super-elderly patients with mCRC, especially with respect to the efficacy of chemotherapy, have been reported. Despite several clinical trials, the efficacy of combination chemotherapy based on oxaliplatin in super-elderly patients remains unelucidated. A previous retrospective study compared the efficacy of FOLFOX in patients aged $\geq 70$ years. The study included 3742 

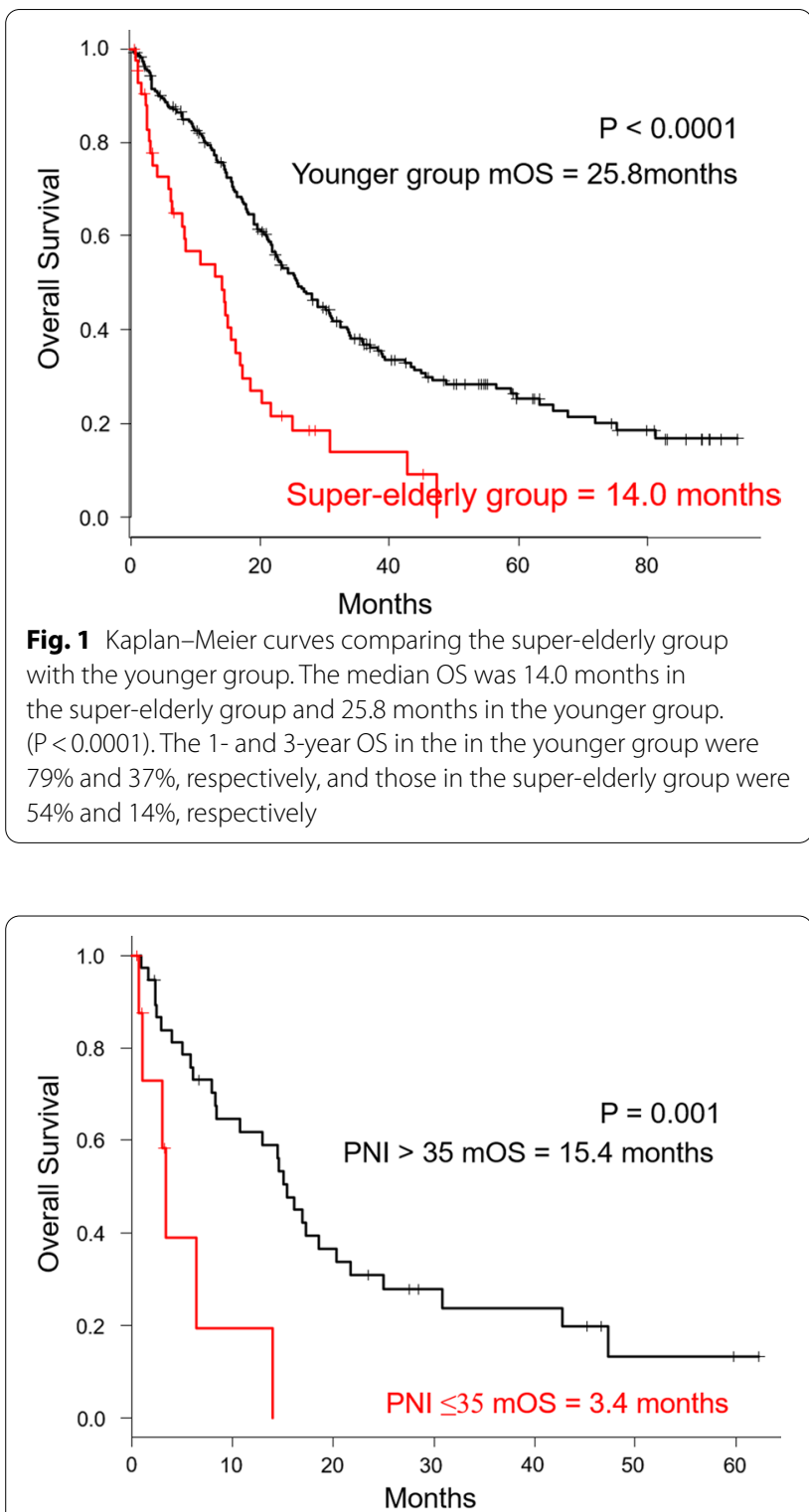

Fig. 2 Kaplan-Meier curves comparing patients with $\mathrm{PNI} \leq 35$ and $\mathrm{PNI}>35$ in super-elderly patients. Patients with $\mathrm{PNI} \leq 35$ had was 3.4 months and Patients with PNI > 35 was 15.4 months in super-elderly patients. The median OS was significantly different between patients with $\mathrm{PNI} \leq 35$ and $\mathrm{PNI}>35(\mathrm{P}=0.001)$

patients (614 patients aged $\geq 70$ years) and showed no differences according to in age progression free-survival (PFS) (hazard ratio: 0.70, age $<70$ years; hazard ratio: 0.65 , age $\geq 70$ years; $P=0.42$ ) and $O S$ (hazard ratio: 0.77 , age $<70$ years; hazard ratio: 0.82 , age $\geq 70$ years; $P=0.79$ ). However, only 15 super-elderly patients were included [24]. Another report evaluated the efficacy and safety of CAPOX-BV (capecitabine plus oxaliplatin and bevacizumab) in patients aged $\geq 75$ years. The study included 36 patients ( 13 patients aged $\geq 80$ years), and 21 patients

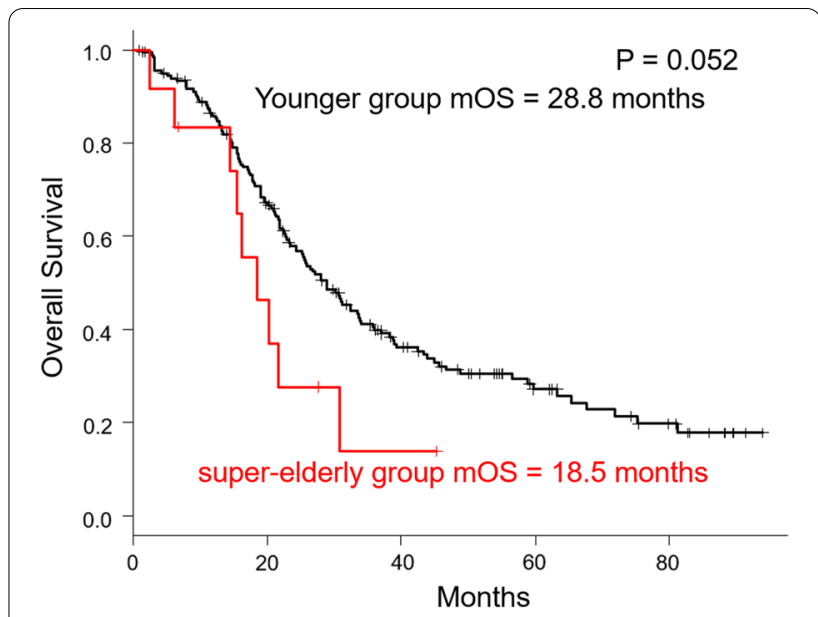

Fig. 3 Kaplan-Meier curves comparing patients who received chemotherapy. The median OS of patients in the super-elderly group who received chemotherapy was 18.5 months, and that of patients in the younger group was 28.8 months, and the difference in median OS between the two groups approached significance $(P=0.052)$

(58.3\%) received second-line chemotherapy. The median PFS and OS was 8.8 months (95\% CI 6.7-10.3 months) and 20.8 months (95\% CI 16.1-26.4 months), respectively [8].

However, there are limited studies of mCRC in the super-elderly group.

The present study showed that the proportion of patients in the super-elderly patients with favorable PS scores $(0-1)$ and good nutritional status were lower than that in the younger group. The super-elderly group was less likely to be treated with chemotherapy than the younger group and had a significantly lower OS than the younger group even in the patients who received chemotherapy. The OS of patients who received chemotherapy tended to be longer than that of those who did not receive chemotherapy; however, there were no significant differences in the super-elderly group. The proportion of super-elderly patients who did not receive treatment was higher than that of younger patients. The proportion of patients treated with chemotherapy was only $28 \%$. In recent reports, the proportion was $22 \%-48 \%$, and the result did not differ [14, 15, 25]. We identified CEA and PNI in the super-elderly group and resection of primary tumor and chemotherapy and albumin level in the younger group as prognostic factors of mCRC. A previous systematic review showed that CEA was an independent prognostic significance factor $[16,26]$. Some previous reports showed that PNI was a prognostic factor of colorectal cancer, resected colorectal cancer, and mCRC $[27,28]$.

In our study, the median OS of super-elderly patients who received chemotherapy was longer than that of 


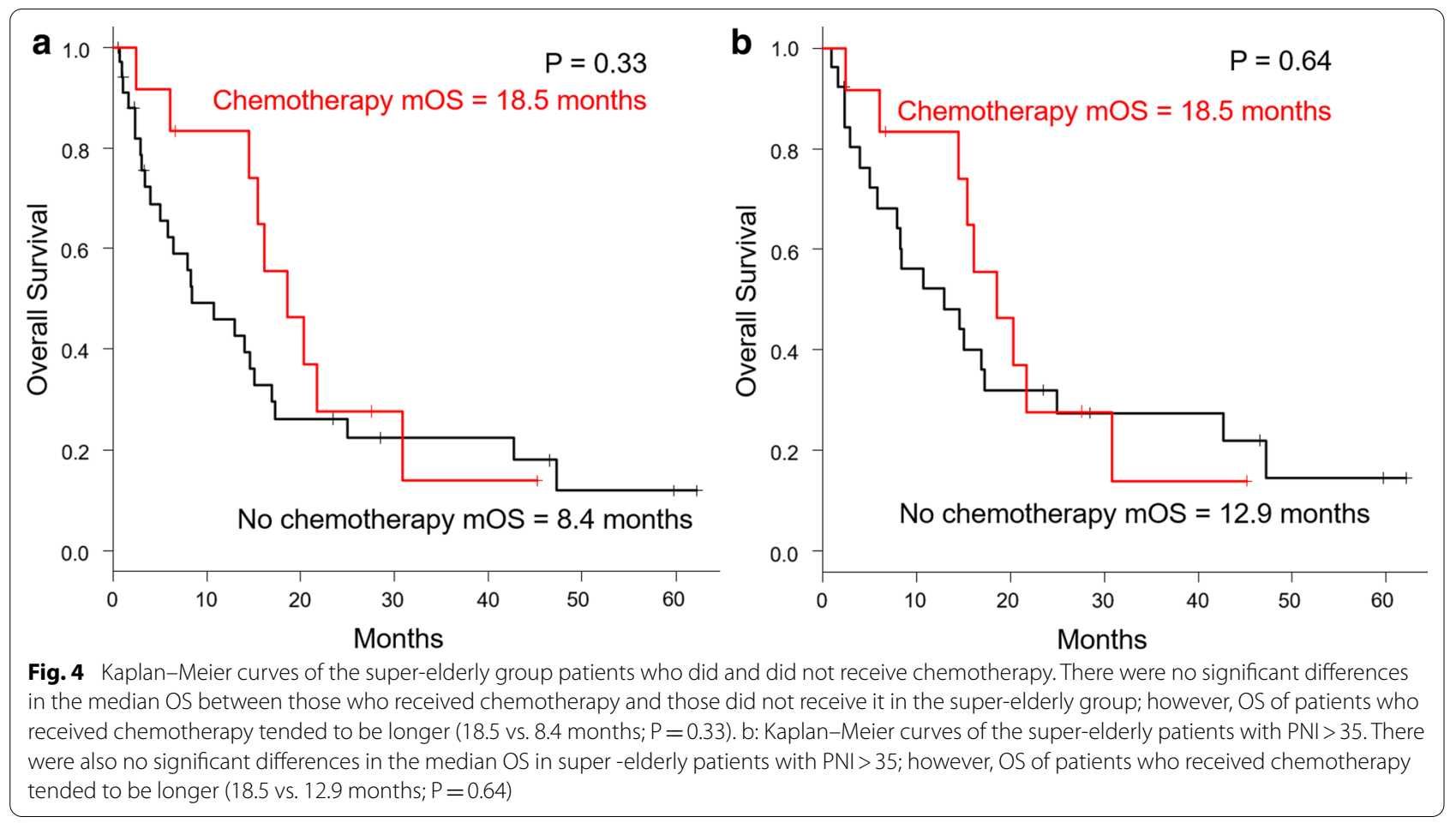

those who did not, although no significant difference was observed (18.5 vs. 8.4 months; $\mathrm{P}=0.33$ ). Grade 3 or 4 adverse events in first-line chemotherapy were reported in $66.7 \%$, and the most frequent adverse event $\geq$ grade 3 reported in the super-elderly group was fatigue (33.3\%). Meanwhile, patients who received mono-chemotherapy did not report any grade 3 or higher adverse event during first-line chemotherapy. In contrast, few studies showed that treatment with chemotherapy was significantly effective in prolonging OS in super-elderly patients. In a previous study of chemotherapy under the age of 75 , the most frequent adverse event $\geq$ grade 3 was neutropenia, with grade 3 neutropenia reported in $11.1 \%$ of patients; meanwhile, grade 3 fatigue was only reported in $2.8 \%$ of patients [8]. In our study, most patients in the super-elderly group $(n=10,83 \%)$ received combination chemotherapy, the most common of which was an oxaliplatin-based regimen. In addition, only 5 (42\%) patients and only $1(8 \%)$ patient in the super-elderly group received second-line and third-line chemotherapy, respectively. Studies conducted in Australia showed that the survival of super-elderly patients who received chemotherapy was similar to that of younger patients. In addition, $74.2 \%$ of super-elderly patients received single-agent chemotherapy, and $35 \%$ and $33 \%$ of these patients received second-line and third-line chemotherapy, respectively. The OS of super-elderly patients who received chemotherapy was 19 months [15]. In our study, the efficacy of chemotherapy could not be shown due to the high number of patients with adverse events $\geq$ grade 3 and low number of patients with thirdline chemotherapy.

The current study had some limitations. First, this was a retrospective and single-center study. Therefore, we could not avoid information bias, particularly regarding adverse effects and discuss complications, which are important factors in studies involving elderly patients. Second, it was not possible to discussion about patients who could be treated with effective chemotherapy because the indications for chemotherapy were not clearly defined. Third, the study included only a small number of patients who received chemotherapy. All the super-elderly patients who received chemotherapy had PNI $>35$, and this may have made it difficult to determine the efficacy of chemotherapy. Therefore, a prospective study should be performed to determine the efficacy of chemotherapy in super-elderly patients with high PNI values.

\section{Conclusions}

Super-elderly patients with $\mathrm{mCRC}$ had worse nutrition status and poorer PS score than younger patients with mCRC, and they had a significantly lower OS than younger patients even though they were treated with chemotherapy. In 
addition, high CEA levels and low PNI were poor prognostic factors of $\mathrm{mCRC}$ in super-elderly patients.

\section{Abbreviations}

CRC: Colorectal cancer; mCRC: Metastatic colorectal cancer; PS: Performance status; CEA: Carcinoembryonic antigen; PNI: Prognostic nutritional index; Cis: Confidence intervals; OS: Overall survival.

\section{Supplementary Information}

The online version contains supplementary material available at https://doi. org/10.1186/s12876-021-01791-9.

Additional file 1: Figure S1: Flowchart of the inclusion and exclusion of patients in the study

Additional file 2: Table S1: Summary of the chemotherapy regimens. Chemotherapy regimens received by patients in the first-, second-, and third-line treatments separated according to those aged $<80$ and $\geq 80$ years.

\section{Acknowledgements}

We would like to thank ENAGO (www.enago.jp) for English language editing

\section{Authors' contributions}

$\mathrm{HH}, \mathrm{YT}$ and AN designed the research study, conceived the manuscript, and analyzed data. MK, HS, El and KS performed chemotherapy and assisted in writing. $\mathrm{HH}$ analyzed and interpreted the patient data and prepared the first draft of the paper. YT and AN were a major contributor in interpreting of the results and reviewed the manuscript. All authors read and approved the final manuscript.

\section{Funding}

The authors declare that this study has received no financial support.

\section{Availability of data and materials}

The data used and analyzed during the current study available from the corresponding author on reasonable request.

\section{Declarations}

\section{Ethics approval and consent to participate}

This study was approved by the institutional review board of Asahi General Hospital (approval no. 2019031914). The requirement of written informed consent was waived due to the use of anonymous data, the retrospective and observational study. Instead of obtaining informed consent, information about the study, and the option to drop out was provided to the participants on the website of Asahi General Hospital. This study was performed in accordance with the standards of the Declaration of Helsinki and the current ethical guidelines.

\section{Consent for publication}

The patients have consented to the submission of the report to the journal.

\section{Competing interests}

The authors declare that they have no competing interests.

\section{Author details}

'Department of Gastroenterology, Graduate School of Medicine, the University of Tokyo, 7-3-1 Hongo, Bunkyo-ku, Tokyo 113-8655, Japan. ${ }^{2}$ Department of Gastroenterology, Asahi General Hospital, Chiba, Japan.

Received: 16 December 2020 Accepted: 26 April 2021 Published online: 01 May 2021

\section{References}

1. Zhao CJ, Li S, Liu Q. Meta-analysis of molecular targeted agents in the treatment of elderly patients with metastatic colorectal cancer: Does the age matter? J Can Res Ther. 2018;14:S79-84. https://doi.org/10.4103/ 0973-1482.158031.

2. Siegel R, Desantis C, Jemal A. Colorectal cancer statistics, 2014. CA Cancer J Clin. 2014;64:104-17. https://doi.org/10.3322/caac.21220.

3. Ministry of Health, Labour and Welfare. Summary of the Simplified Life Chart. https://www.mhlw.go.jp/toukei/saikin/hw/life/life17/dl/life17-15. pdf. Accessed 10 Aug 2020.

4. Angenete E. Reducing morbidity and mortality in the elderly population with colorectal cancer. Colorectal Dis. 2020;22:362-3. https://doi.org/10. 1111/codi.15029.

5. Sawhney R, Sehl M, Naeim A. Physiologic aspects of aging: impact on cancer management and decision making, part I. Cancer J. 2005;11:44960. https://doi.org/10.1097/00130404-200511000-00004.

6. Sorbye H, Cvancarova M, Qvortrup C, Pfeiffer P, Glimelius B. Age-dependent improvement in median and long-term survival in unselected population-based Nordic registries of patients with synchronous metastatic colorectal cancer. Ann Oncol. 2013;24:2354-60. https://doi.org/10. 1093/annonc/mdt197.

7. Cunningham D, Lang I, Marcuello E, et al. Bevacizumab plus capecitabine versus capecitabine alone in elderly patients with previously untreated metastatic colorectal cancer (AVEX): an open-label, randomised phase 3 trial. Lancet Oncol. 2013;14:1077-85. https://doi.org/10.1016/S14702045(13)70154-2.

8. Petrioli R, Francini E, Cherri S, et al. Capecitabine plus oxaliplatin and bevacizumab, followed by maintenance treatment with capecitabine and bevacizumab for patients aged $>75$ years with metastatic colorectal cancer. Clin Colorectal Cancer. 2018;17:e663-9. https://doi.org/10.1016/j. clcc.2018.07.002

9. Yang L, Ma Q, Yu YY, et al. Efficacy of surgery and adjuvant therapy in older patients with colorectal cancer: a STROBE-compliant article. Medicine (Baltimore). 2014;93:e266. https://doi.org/10.1097/MD.0000000000 000266.

10. Folprecht G, Cunningham D, Ross P, et al. Efficacy of 5-fluorouracil-based chemotherapy in elderly patients with metastatic colorectal cancer: a pooled analysis of clinical trials. Ann Oncol. 2004;15:1330-8. https://doi. org/10.1093/annonc/mdh344.

11. Sundararajan V, Mitra N, Jacobson JS, Grann VR, Heitjan DF, Neugut AI. Survival associated with 5-fluorouracil-based adjuvant chemotherapy among elderly patients with node-positive colon cancer. Ann Intern Med. 2002;136:349-57. https://doi.org/10.7326/0003-4819-136-5-20020 3050-00007.

12. McKibbin T, Frei CR, Greene RE, Kwan P, Simon J, Koeller JM. Disparities in the use of chemotherapy and monoclonal antibody therapy for elderly advanced colorectal cancer patients in the community oncology setting. Oncologist. 2008;13:876-85. https://doi.org/10.1634/theoncologist. 2008-0061.

13. Golfinopoulos V, Pentheroudakis G, Pavlidis N. Treatment of colorectal cancer in the elderly: a review of the literature. Cancer Treat Rev. 2006;32:1-8. https://doi.org/10.1016/j.ctrv.2005.10.002.

14. Jung $Y H$, Kim JY, Jang $Y N$, et al. Clinical characteristics and treatment propensity in elderly patients aged over 80 years with colorectal cancer. Korean J Intern Med. 2018;33:1182-93. https://doi.org/10.3904/kjim.2016. 181.

15. Kumar R, Jain K, Beeke C, et al. A population-based study of meta-static colorectal cancer in individuals age $\geqq 80$ years. Cancer. 2013;119:722-8. https://doi.org/10.1002/cncr.27802.

16. Zhang S, Gao F, Luo J, Yang J. Prognostic factors in survival of colorectal cancer patients with synchronous liver metastasis. Colorectal Dis. 2010;12:754-61. https://doi.org/10.1111/j.1463-1318.2009.01911.x.

17. Zlobec I, Bihl MP, Schwarb H, Terracciano L, Lugli A. Clinicopathological and protein characterization of BRAF- and K-RAS-mutated colorectal cancer and implications for prognosis. Int J Cancer. 2010;127:367-80. https:// doi.org/10.1002/ijc.25042.

18. Luvián-Morales J, González-Trejo S, Carrillo JF, et al. Association of the prognostic nutritional index and overall survival in patients with colorectal cancer: A STROBE compliant retrospective cohort study. Cancer Med. 2019;8:3379-88. https://doi.org/10.1002/cam4.2212. 
19. Oken MM, Creech RH, Tormey DC, et al. Toxicity and response criteria of the Eastern Cooperative Oncology Group. Am J Clin Oncol. 1982:5:649-55.

20. Hamilton SR, Bosman FT, Boffetta P, et al. Carcinoma of the colon and rectum. In: Bosman FT, Carneiro F, Hruban $\mathrm{RH}$, Theise ND, editors., et al., WHO classification of tumours of the digestive system. Lyon: IARC Press; 2010

21. Aparicio T, Ducreux M, Faroux R, et al. Overweight is associated to a better prognosis in metastatic colorectal cancer: a pooled analysis of FFCD trials. Eur J Cancer. 2018;98:1-9. https://doi.org/10.1016/j.ejca.2018.03.031.

22. Sun G, Li Y, Peng Y, et al. Impact of the preoperative prognostic nutritional index on postoperative and survival outcomes in colorectal cancer patients who underwent primary tumor resection: a systematic review and meta-analysis. Int J Colorectal Dis. 2019;34:681-9. https://doi.org/10. 1007/s00384-019-03241-1.

23. Arnold D, Lueza B, Douillard JY, et al. Prognostic and predictive value of primary tumour side in patients with RAS wild-type metastatic colorectal cancer treated with chemotherapy and EGFR directed antibodies in six randomized trials. Ann Oncol. 2017;28:1713-29. https://doi.org/10.1093/ annonc/mdx 175 .

24. Goldberg RM, Tabah-Fisch I, Bleiberg H, et al. Pooled analysis of safety and efficacy of oxaliplatin plus fluorouracil/leucovorin administered bimonthly in elderly patients with colorectal cancer [published correction appears in Journal of Clinical Oncology. 2008 Jun 10;26(17):2925-6]. J Clin Oncol 2006;24:4085-91. https://doi.org/10.1200/ JCO.2006.06.9039.

25. Oh BY, Huh JW, Kim HC, et al. Oncologic outcome of colorectal cancer patients over age 80: a propensity score-matched analysis. Int J Colorectal Dis. 2018;33:1011-8. https://doi.org/10.1007/s00384-018-3028-4.

26. Stillwell $A P, H o Y H$, Veitch C. Systematic review of prognostic factors related to overall survival in patients with stage IV colorectal cancer and unresectable metastases. World J Surg. 2011;35:684-92. https://doi.org/ 10.1007/s00268-010-0891-8.

27. LvY, Ji ML, Feng QY, et al. Combined test of third lumbar skeletal muscle index and prognostic nutrition index improve prognosis prediction power in resected colorectal cancer liver metastasis. Aging (Albany NY). 2019;11:10301-15. https://doi.org/10.18632/aging.102457.

28. Song A, Eo W, Lee S. Comparison of selected inflammation-based prognostic markers in relapsed or refractory metastatic colorectal cancer patients. World J Gastroenterol. 2015;21:12410-20. https://doi.org/10. 3748/wjg.v21.i43.12410.

\section{Publisher's Note}

Springer Nature remains neutral with regard to jurisdictional claims in published maps and institutional affiliations.
Ready to submit your research? Choose BMC and benefit from:

- fast, convenient online submission

- thorough peer review by experienced researchers in your field

- rapid publication on acceptance

- support for research data, including large and complex data types

- gold Open Access which fosters wider collaboration and increased citations

- maximum visibility for your research: over $100 \mathrm{M}$ website views per year

At BMC, research is always in progress.

Learn more biomedcentral.com/submissions 